\author{
A - preparing concepts \\ $\mathrm{B}$ - formulating methods \\ $\mathrm{C}$ - conducting research \\ $\mathrm{D}$ - processing results \\ E - interpretation \\ and conclusions \\ $\mathrm{F}$ - editing the final \\ version
}

\section{Factors determining the functional abilities of patients after stroke}

\author{
Julia Kubielska*A-D iD, Joanna KostkaA-C,E-F iD, Elżbieta Miller ${ }^{B, E-F}$ iD \\ Department of Neurological Rehabilitation, Medical University of Łódz, \\ Milionowa 14, 93-11 Łódz
}

*Correspondence: Julia Kubielska; Department of Neurological Rehabilitation, Medical University of Łódz, Milionowa 14, 93-11 Łódz; email: jkubielska@onet.pl

\title{
Abstract
}

Introduction: The purpose of the study was to assess the functional abilities of patients after stroke and to identify factors that affect it.

Material and methods: The study was performed on 40 patients after stroke. To assess functional ability the Rivermead Motor Assessment (RMA), Barthel Index (BI), Tinetti test, and Up\&Go test were used. The maximum muscle power (Pmax), optimal shortening velocity (Vopt), muscle strength, one-leg standing test, Geriatric Depression Scale (GDS), pain assessment (Numeric Pain Scale), nutrition assessment (Mini Nutritional Assessment Scale - MNA) were also performed.

Results: Functional performance was influenced by: knee flexors on the affected side (correlations respectively: RMA rho $=0.37 ; \mathrm{p}=0.04 ;$ Tinetti test rho $=0.44 ; \mathrm{p}<0.01 ; \mathrm{Up} \&$ Go test rho $=-0.56 ; \mathrm{p}<0.001)$, balance time on a non-affected leg $(\mathrm{RMA}$ rho $=0.38 ; \mathrm{p}=0.03 ; \mathrm{BI}$ rho $=0.41 ; \mathrm{p}=0.01$; test Tinetti rho $=0.64 ; \mathrm{p}<0.001 ;$ Up\&Go test rho $=-0.47$; $\mathrm{p}=0.003$ ), Pmax (RMA rho $=0.35 ; \mathrm{p}=0.04$; Tinetti test rho $=0.49 ; \mathrm{p}<0.01 ;$ Up\&Go test rho $=-0.63 ; \mathrm{p}<0.001$ ), reporting problems with sitting and standing up (RMA $p=0.003$; Tinetti test $p=0.02$; Up\&Go test $p=0.049$ ), using orthopedic assistance (RMA global functions $\mathrm{p}=0.01$; RMA lower limb and torso $\mathrm{p}=0.04$; $\mathrm{BI} \mathrm{p}=0.003$; Tinetti test $\mathrm{p}<0.001$, Up\&Go test $p<0.001)$. The MNA result was correlated with RMA (rho $=0.36 ; p<0.04$ ), no correlation was obtained for any of the functional tests with the extensor muscle strength on the non-affected side, GDS and pain level.

Conclusions: The functional ability of stroke patients is affected by knee flexors on the affected side, the ability to maintain balance, and maximum muscle power. People, who reported problems with sitting and standing up and using orthopedic assistance, are characterized by worse ability.

\section{Keywords: muscle power, muscle strength, balance, strength measurement, functional deficits}

\section{Introduction}

Stroke is the third most common cause of death right after heart disease and cancer. It is the most common cause of disability in people over 40 [1].
As a consequence of stroke, not only spheres of human functioning, which were controlled by the damaged area of the brain, are impaired, but also (through the network of connections) the parts cooperating with it. These changes concern both motor functioning 
and mental, cognitive and, consequently social functions. Pathological changes in the nervous system cause a slowdown in nerve conduction, deterioration of stimulus integration and processing, prolonged reaction time as well as a lack of ability to maintain coordination of movements, which increases the risk of falls [2].

The muscles of the limbs on the affected side are weakened, especially shortly after the stroke. Muscle strength on the side opposite the damaged part of the brain is up to $60 \%$ lower compared to the muscle strength of healthy people and tends to be more weakened proximal than distal. The torso muscles are also weakened. Muscle dysfunctions are associated with consequences while performing daily activities [3].

Patient gait is characterized by changes in length and symmetry of the steps, duration of gait phases, overlo$\mathrm{ad}$, and lengthening of the supportive limb. It requires a lot of effort and is also characterized by low speed. Patient is often forced to use orthopedic aids during locomotion [4]. All those can significantly affect the deterioration of functional performance i.e. the ability to be independent in basic and compound daily activities [5].

The purpose of the study was to assess the functional ability of stroke patients and to identify factors that affect it.

\section{Material and methods}

Tests were performed on 40 adults of both sexes after an ischemic or haemorrhagic stroke during the last four months hospitalized in the Clinic of Neurological Rehabilitation at the Jonscher Municipal Medical Center dr Karol Jonscher in Łódz. The tests were carried out on persons capable of understanding and executing commands and without general contraindications to perform stress tests. The study excluded people with severe pain, a significant limitation of the lower limb movement ranges, and large changes in muscle tone to a degree that limited the ability to perform planned tests and examinations. All patients gave written consent to participate in the study and obtained the consent of the main doctor. The project was approved by the Bioethics Committee of the Medical University of Łódz (RNN/130/17/KE from April 17, 2017).

All patients completed a questionnaire that contained questions about their basic data, characteristics of stroke, current functional ability, comorbidities, and lifestyle.

To assess functional ability the 20-point Barthel Index [6], Rivermead Motor Assessment (RMA) [7], oneleg standing test [8], Up\&Go [9] test and Tinetti test [10] were used.

To assess the maximum power (Pmax) and optimal shortening velocity of the knee extensor (Vopt) the
Monark type cyclo ergometer equipped with a force sensor (Interface MFG type, Scottsdale, Ariz.USA) and a speed sensor (Hengstler type RIS IP50, 100* $\mathrm{rev}^{-1}$, Aldingen, Germany) was used. Two 8-second trials with 0.25 and $0.35 \mathrm{~N} / \mathrm{kg}$ body weight or less $(0.1-0.2 \mathrm{~N} / \mathrm{kg}$ body weight) were performed when the patient had difficulty initiating movement at a given load. The test consisted of riding a cyclo ergometer at the maximum possible speed in 8s. Mathematical analysis of the results of the V-P (speed-power) combination recorded during two tests allows to determine the relationship between power and speed. The highest level of maximum power (Pmax) and optimal shortening velocity (Vopt-speed at which the power reaches maximum values) was calculated from the third-degree polynomial regression. Pmax is presented in watts (W). The optimal shortening velocity (Vopt) is given as the number of revolutions per minute (rpm) [11].

To assess the mental state the Geriatric Depression Scale (GDS) was used, a 15-point version [10]. The level of pain was determined using the Numeric Pain Scale [12]. The Mini Nutritional Assessment Scale (MNA) was used to assess nutritional status [10]. Muscle strength of knee extensors and flexors was measured using a Hoggan microFET2 dynamometer with a strain gauge sensor. Seated patients with thighs supported and lower legs following verbal instructions were supposed to perform an extension test and then bend the knee by pressing the device with as much force as possible for about 5 seconds. The points of application of the dynamometer are the distal part of the front (for measuring the extensor strength) and the rear (for measuring the flexor strength) surface of the lower leg. Each patient had two attempts to measure and a better result was used for the study. Muscle strength is given in newtons.

\section{Statistical analysis}

Collected data was subject of statistical analysis. The data was checked for normality of distribution and equality of variances. The results are presented in the form of an average, standard deviation, and minimum and maximum values. The impact of quantitative factors on the results of functional tests and muscle function parameters was calculated using the Spearman correlation coefficient while the impact of qualitative factors was determined using the Kruskal-Wallis test. The level of statistical significance was set to $\mathrm{p} \leq 0.05$.

\section{Results}

The characteristics of the study group are presented in Table 1. 
Tab. 1. Characteristics of the study group

\begin{tabular}{lcc}
\hline & Average \pm standard deviation & Minimum value - maximum value \\
\hline Age & $67.28 \pm 8.06$ & $53-85$ \\
Body weight $(\mathrm{kg})$ & $77.60 \pm 13.13$ & $50-117$ \\
Growth $(\mathrm{cm})$ & $168.83 \pm 8.13$ & $156-184$ \\
BMI & $27.22 \pm 4.29$ & $20.03-40.9$ \\
Number of years of education & $10.83 \pm 2.24$ & $8-16$ \\
Number of strokes & $1.35 \pm 0.89$ & $1-6$ \\
Number of weeks after stroke & $6.11 \pm 4.17$ & $1.5-20$ \\
Number of comorbidities & $2.05 \pm 1.34$ & $0-5$ \\
GDS Scale & $4.48 \pm 2.31$ & $1-11$ \\
MNA Scale & $24.26 \pm 2.47$ & $18-28$ \\
Numeric Pain Scale & $5.07 \pm 2.81$ & $1-10$ \\
Tinetti Test - gait rating & $8.95 \pm 3.09$ & $2-12$ \\
Tinetti Test - balance rating & $11.33 \pm 3.68$ & $2-16$ \\
Tinetti Test - sum & $20.28 \pm 6.24$ & $4-28$ \\
Up\&go Test $(\mathrm{s})$ & $12.19 \pm 6.82$ & $5.39-37.22$ \\
Extensors strenght - non affected side $(\mathrm{N})$ & $206.33 \pm 61.92$ & $80-319$ \\
Extensors strenght - affected side $(\mathrm{N})$ & $165.07 \pm 69.43$ & $46.2-306.9$ \\
Flexors strenght - non affected side $(\mathrm{N})$ & $139.82 \pm 47.65$ & $51.1-246$ \\
Flexors strenght - affected side $(\mathrm{N})$ & $112.15 \pm 53.46$ & $15.5-215.7$ \\
Pmax $(W)$ & $187.2 \pm 91.77$ & $41.28-371.82$ \\
Vopt (rpm) & $50.09 \pm 17.91$ & $19.47-83.1$ \\
Bartel Index & $12.34 \pm 5.12$ & $2-19$ \\
RMA global functions & $8.35 \pm 2.66$ & $2-12$ \\
RMA lower limb and torso & $6.97 \pm 2.82$ & $1-11$ \\
RMA upper limb & $6.74 \pm 4.49$ & $0-15$ \\
RMA sum & $18.75 \pm 11.07$ & $0-36$ \\
\hline
\end{tabular}

BMI - Body Mass Index, GDS - Geriatric Depression Scale, MNA - Mini Nutritional Assessment, Pmax - maximum power, Vopt optimal shortening velocity, RMA - Rivermead Motor Assessment.

14 women and 26 men participated in the study. Patients were diversified in terms of education: 12 of them had primary education, 16 secondary, 10 vocational, and 2 higher. Thirty-two of the respondents live on retirement or disability pensions, 4 work physically, 2 mentally and 2 are unemployed. Many patients are additionally burdened with comorbidities: 28 patients have hypertension, 2 have hypercholesterolemia, 5 have had a myocardial infarction, 5 have coronary heart disease, 5 have heart failure, 2 lung disease, 15 diabetes, 8 osteoarthritis, 1 osteoporosis, 10 stomach disease or duodenum and one person was diagnosed with cancer. 11 patients in the immediate family had a stroke. Thirteen people used additional orthopedic help. As many as 26 patients are addicted to smoking cigarettes or have been addicted in the past. Twenty-five respondents try to do physical activity regularly, the remaining 15 people do not do it at all. Four people from the study group regularly drink alcohol in significant quantities.

Factors determining the functional ability of stroke patients are presented in Tables 2 and 3.

Patients ages do not correlate with most tests except for the Up\&Go test (positive correlation). Anthropometric indicators (height, weight, BMI) and the number of years of education do not affect the results of functional tests. The largest number of functional tests correlate to maximum power and knee flexor strength on the affected side (patients who generate more power and strength obtain better results in RMA, Tinetti test and Up\&Go test) and static balance indicators (one-leg 
Tab. 2. Quantitative factors affecting the functional ability of stroke patients

\begin{tabular}{|c|c|c|c|c|}
\hline & RMA sum & Barthel Index & Tinetti Test & Test Up\&go \\
\hline Age & ns & ns & ns & $\begin{array}{c}\text { rho }=0.31 \\
\mathrm{p}=0.05\end{array}$ \\
\hline Growth & ns & ns & ns & ns \\
\hline Body weight & ns & ns & ns & ns \\
\hline BMI & ns & ns & ns & ns \\
\hline Number of years of education & ns & ns & ns & ns \\
\hline Time from stroke (weeks) & ns & ns & ns & ns \\
\hline Number of stroke & ns & ns & ns & ns \\
\hline Extensors strenght - non affected side & ns & ns & ns & ns \\
\hline Extensors strenght - affected side & ns & ns & ns & $\begin{array}{c}\text { rho }=-0.34 \\
\mathrm{p}=0.05\end{array}$ \\
\hline Flexors strenght - non affected side & ns & ns & $\begin{array}{c}\text { rho }=0.32 \\
p=0.05\end{array}$ & $\begin{aligned} \text { rho } & =-0.44 \\
\mathrm{p} & <0.01\end{aligned}$ \\
\hline Flexors strenght - affected side (N) & $\begin{array}{c}\text { rho }=0.37 \\
p=0.04\end{array}$ & ns & $\begin{array}{c}\text { rho }=0.44 \\
\mathrm{p}<0.01\end{array}$ & $\begin{array}{c}\text { rho }=-0.56 \\
\mathrm{p}<0.001\end{array}$ \\
\hline Standing time on a non-affected leg & $\begin{array}{c}\text { rho }=0.38 \\
\mathrm{p}=0.03\end{array}$ & $\begin{array}{c}\text { rho }=0.41 \\
\mathrm{p}=0.01\end{array}$ & $\begin{array}{c}\text { rho }=0.64 \\
\mathrm{p}<0.001\end{array}$ & $\begin{array}{c}\text { rho }=-0.47 \\
p=0.003\end{array}$ \\
\hline Standing time on a affected leg & ns & $\begin{array}{c}\text { rho }=0.31 \\
\mathrm{p}=0.01\end{array}$ & $\begin{array}{c}\text { rho }=0.81 \\
\mathrm{p}<0.001\end{array}$ & $\begin{array}{c}\text { rho }=-0.76 \\
\mathrm{p}<0.001\end{array}$ \\
\hline Numeric Pain Scale & ns & ns & ns & ns \\
\hline GDS Scale & ns & ns & ns & ns \\
\hline MNA Scale & $\begin{array}{c}\text { rho }=0.36 \\
\mathrm{p}=0.04\end{array}$ & ns & ns & ns \\
\hline Pmax & $\begin{array}{l}\text { rho }=0.35 \\
\mathrm{p}=0.04\end{array}$ & ns & $\begin{array}{c}\text { rho }=0.49 \\
\mathrm{p}<0.01\end{array}$ & $\begin{array}{c}\text { rho }=-0.63 \\
\mathrm{p}<0.001\end{array}$ \\
\hline Vopt & ns & ns & $\begin{array}{c}\text { rho }=0.43 \\
\mathrm{p}<0.01\end{array}$ & $\begin{array}{c}\text { rho }=-0.55 \\
\mathrm{p}<0.001\end{array}$ \\
\hline
\end{tabular}

ns - no relationship at statistically significant level, BMI - Body Mass Index, GDS - Geriatric Depression Scale, MNA - Mini Nutritional Assessment, Pmax - maximum power, Vopt - optimal shortening velocity, RMA - Rivermead Motor Assessment.

standing test on both sides stronger and weaker). Functional ability is not affected by the GDS Scale and the presence of patients' pain. It applies to few patients and do not always occur in the lower limb or torso, which could affect the test results. There was no relationship between the extensor muscle strength on the stronger side and the results of functional tests and the relationship on the border of statistical significance with only one test (Up\&Go) for the extensor muscle strength on the weaker side (Table 2).

Among the qualitative variables (Table 3) the most important relationship with functional ability is the use of orthopedic aids, reporting problems with standing up and sitting, and in individual cases the occurrence of additional diseases (NT, myocardial infarction and gastrointestinal diseases).

\section{Discussion}

The results of the presented studies indicate that the main factor affecting functional ability in patients after stroke is muscle function and particularly maximum power and muscle strength. Impaired muscle function (including weakness of muscle strength and power) associated with hemiplegia is a common occurrence in the group of patients after stroke. Structural changes in muscle tissue are observed very early - even 4 hours after the stroke incident, which may be the result of changes in nerve conduction, disruption, inflammatory changes, and in the long run the effect of inactivity and changes in muscle tone [13]. The literature also draws attention to the initiation of catabolic processes after a stroke which also leads to a loss of muscle mass and function 
Tab. 3. Qualitative factors affecting the functional ability of stroke patients (Kruskal-Wallis)

\begin{tabular}{|c|c|c|c|c|}
\hline & RMA sum & Barthel Index & Tinetti Test & Up\&Go Test \\
\hline $\begin{array}{l}\text { Sex } \\
\text { Female }-14 \\
\text { Male }-26\end{array}$ & ns & ns & ns & ns \\
\hline $\begin{array}{l}\text { Education } \\
\text { Primary } \\
\text { Vocational } \\
\text { Secondary } \\
\text { Higher }\end{array}$ & ns & $\begin{array}{c}\mathrm{P}=0.02 \\
11.27 \pm 3.77 \\
8.9 \pm 6.12 \\
14.87 \pm 4.0 \\
16.6 \pm 2.12\end{array}$ & ns & ns \\
\hline $\begin{array}{l}\text { Orthopedic aids } \\
\text { No }-27 \\
\text { Yes }-13\end{array}$ & ns & $\begin{array}{c}\mathrm{P}=0.003 \\
14.04 \pm 4.28 \\
8.67 \pm 4.98\end{array}$ & $\begin{array}{c}\mathrm{P}<0.001 \\
23.30 \pm 3.59 \\
14.0 \pm 5.94\end{array}$ & $\begin{array}{c}\mathrm{P}<0.001 \\
9.51 \pm 3.63 \\
17.76 \pm 8.54\end{array}$ \\
\hline $\begin{array}{l}\text { Reporting problems with sitting } \\
\text { and standing up } \\
\text { No }-26 \\
\text { Yes }-14\end{array}$ & $\begin{array}{c}\mathrm{P}=0.03 \\
24.45 \pm 7.00 \\
17.67 \pm 9.08\end{array}$ & $\mathrm{~ns}$ & $\begin{array}{c}\mathrm{P}=0.02 \\
22.35 \pm 4.05 \\
16.43 \pm 7.79\end{array}$ & $\begin{array}{c}\mathrm{P}=0.049 \\
10.23 \pm 4.07 \\
15.83 \pm 9.27\end{array}$ \\
\hline $\begin{array}{l}\text { Hypertension } \\
\text { No }-12 \\
\text { Yes }-28\end{array}$ & ns & ns & $\begin{array}{c}\mathrm{P}<0.05 \\
22.92 \pm 4.54 \\
19.14 \pm 6.59\end{array}$ & ns \\
\hline $\begin{array}{l}\text { Diabetes } \\
\text { No }-25 \\
\text { Yes }-15\end{array}$ & ns & ns & ns & ns \\
\hline $\begin{array}{l}\text { Myocardial infarction } \\
\text { No }-35 \\
\text { Yes }-5\end{array}$ & ns & $\begin{array}{c}\mathrm{P}=0.04 \\
11.74 \pm 5.10 \\
16.6 \pm 3.21\end{array}$ & ns & $\mathrm{ns}$ \\
\hline $\begin{array}{l}\text { Coronary artery disease } \\
\text { No }-35 \\
\text { Yes }-5\end{array}$ & ns & ns & ns & ns \\
\hline $\begin{array}{l}\text { Cilcuratory failure } \\
\text { No }-35 \\
\text { Yes }-5\end{array}$ & ns & ns & ns & ns \\
\hline $\begin{array}{l}\text { Degenerative disease } \\
\text { No }-32 \\
\text { Yes }-8\end{array}$ & ns & ns & ns & $\mathrm{ns}$ \\
\hline $\begin{array}{l}\text { Gastrointestinal disease } \\
\text { No }-31 \\
\text { Yes }-9\end{array}$ & ns & ns & $\begin{array}{c}\mathrm{P}<0.05 \\
21.06 \pm 6.42 \\
17.56 \pm 4.92\end{array}$ & ns \\
\hline
\end{tabular}

ns - no relationship at statistically significant level, RMA - Rivermead Motor Assessment.

[14]. Despite the fact that according to other authors, the muscle strength deficit affects both the directly affected and the opposite side [3], in our study functional ability after stroke was more affected by the strength of the muscles on the affected side primarily the knee flexor muscles and the strength of the knee extensor muscles on the non-affected side was unaffected.

These results are consistent with the results of other studies [15]. Based on research conducted among stroke patients admitted to the Rehabilitation Clinic it was shown that the strength of the knee flexors on the affected side is apparently correlated with the results of functional tests of patients after a stroke. This is probably due to the important role this muscle group plays primarily during walking. Limitation of the range of knee bending during the transfer phase caused by among others deficiency in muscle strength (but also a change in muscle tone) disturbs the transfer phase during walking (functional shortening of the limb) [16]. These muscles prevent the occurrence of hyperextension in 
the knee during gait - they eccentrically control knee flexion in the support phase [17].

The results of the conducted research also suggest that the most important factor affecting the functional ability of stroke patients is maximum muscle power. Patients generating lower quadriceps muscle power, obtained weaker RMA results as well as the Tinetti test and the Up\&Go test. Our previous studies [18] indicate a significant deficit of muscle power in stroke patients. People who suffered from a stroke achieved only $49.6 \%$ muscle power comparing to their peers. In this study muscle power has a greater impact on functional ability than the age of the patients which in the general population is a significant determinant of ability in both ADL and IADL [19]. Muscle power is necessary for everyday activities that require the generation of strength in a relatively short time (e.g. getting up from a chair, walking, reaction to the threat of falling) and more than strength disappears with age. Research indicates that power can determine functional ability to a greater extent than strength $[11,20]$. In the InCHIANTI study conducted in the elderly population of Italy low muscle strength was 2-3 times more than low strength related to the level of functional ability. Because strength is an important determinant of muscle power resistance training increasing strength can also improve muscle power. Research on resistance training in people after stroke shows that it can lead to an increase in muscle strength which also improves the results of functional tests. Despite doubts about the safety and legitimacy of such training after stroke, no increase in spasticity or other adverse events were recorded (even under the influence of highintensity exercises) in this group of patients $[21,22]$.

Another important factor determining functional ability in the examined group of patients was the ability to maintain balance (standing time on one leg). Balance deficits mean that the incidence of falls in this group is higher than in the general population [23]. Balance disorders after stroke result from changes in the central nervous system, but may also be associated with deficits in muscle strength and power $[23,24]$. The ability to maintain body balance is one of the basic coordination components that ensures proper human functioning. Balance is necessary to maintain proper body posture and movement. During locomotion, it determines the quality of gait and prevents uncontrolled falls and injuries [25]. Therefore the inclusion in the rehabilitation program of exercises to improve balance can contribute not only to the improvement of functional abilities, but also patient safety. Patients who used ancillary devices were characterized by weaker functional ability. These devices are generally recommended to improve ability and reduce the risk of falling. These recommendations usually apply to people with limited mobility which may explain the results of our research as well as research by other authors $[26,27]$. When choosing the right orthopedic equipment care should be taken and detailed instructions regarding the use of equipment should be given. There have been reports that in some situations ancillary devices may disrupt the ability to maintain balance and place too much burden on the patient both in weight and coordination [27]. This is especially relevant to stroke patients who are often accompanied by cognitive impairment.

\section{Conclusions}

The greatest impact on functional ability in stroke patients is due to the strength of the knee flexors on the affected side, the ability to maintain balance and maximum muscle power. People who reported problems with sitting and standing up and using orthopedic assistance are characterized by worse ability.

\section{Funding}

This research received no external funding.

\section{Conflicts of interest}

The authors declare no conflict of interest.

\section{References}

1. Brola W, Fudala M. Stroke prevention - the role of a family doctor. Przegl Med U Rzesz i Nar Ins Lek. 2011; 1: 128-40.

2. Skalska A. Restriction of functional ability of the elderly. Zdr Publ Zarz. 2011; 9(1): 50-9.

3. Bohannon WR. Muscle strength and muscle training after stroke. J Rehabil Med. 2007; 39(1): 14-20.

4. Drużbicki M, Kwolek A, Przysada G, Pop T, Depa A. Assessment of gait function in patients with hemiparesis after stroke in the chronic period. Przegl Med U Rzesz. 2010; 2: 145-51.

5. Wysokiński M, Fidecki W. Assessment of functional ability of elderly patients. In: Cybulski M, KrajewskaKułak E, editors. Elderly care: a guide for the therapeutic team. Warsaw: PZWL; 2016. p. 29-44.

6. Kwolek A. Physiotherapy in neurology and neurosurgery. Warsaw: PZWL; 2012.

7. Klimkiewicz P, Klimkiewicz R, Jankowska A, Kubsik A, Widłak P, Łukasiak $€$ et al. Evaluation of the functional state after neurorehabilitation of patients after ischemic stroke. Wiad Lek. 2018; 71(2): 271-7.

8. Zasadzka E, Wieczorowska-Tobis K. One-leg standing test as a tool for assessing the balance of the elderly. Geriatr. 2012; 6: 244-9. 
9. Ronikier A. Functional diagnostics in physiotherapy. Warsaw: PZWL; 2012.

10. Wieczorowska-Tobis K, Talarska D. Geriatrics and geriatric nursing. Warsaw: PZWL; 2014.

11. Kostka JS, Czernicki JW, Kostka TJ. Association of muscle strength, power, and optimal shortening velocity with functional abilities of women with chronic osteoarthritis participating in a multi-modal exercise program. J Aging Phys Act. 2014; 22(4): 564-70.

12. Mayzner-Zawadzka E. Clinical anesthesiology with elements of intensive therapy and pain management. Volume 1 and 2. Warsaw: PZWL; 2009.

13. Scherbakov N, Doehner W. Sarcopenia in stroke-facts and numbers on muscle loss accounting for disability after stroke. J Cachexia Sarcopenia Muscle. 2011; 2(1): 5-8.

14. Springer J, Schust S, Peske K, Tschirner A, Rex A, Engel $\mathrm{O}$ et al. Catabolic signaling and muscle wasting after acute ischemic stroke in mice: indication for a strokespecific sarcopenia. Stroke. 2014; 45(12): 3675-8.

15. Kostka J, Czernicki J, Pruszyńska M, Miller E. Strength of knee flexors of the paretic limb as an important determinant of functional status in post-stroke rehabilitation. Neurol Neuroch Pol. 2017, 51(3): 227-33.

16. Nasciutti-Prudente C, Oliveira FG, Houri SF, de Paula Goulart FR, Neto MH, Teixeira-Salmela LF. Relationships between muscular torque and gait speed in chronic hemiparetic subjects. Disabil Rehabil. 2009; 31(2): 103-8.

17. Bleyenheuft C, Bleyenheuft Y, Hanson P, Deltombe $\mathrm{T}$. Treatment of genu recurvatum in hemiparetic adult patients: a systematic literature review. Ann Phys Rehabil Med. 2010; 53(3): 189-99.

18. Kostka J, Niwald M, Guligowska A, Kostka T, Miller E. Muscle power, contraction velocity and functional performance after stroke. Brain Behav. 2019; 9(4).
19. Connolly D, Garvey J, McKee G. Factors associated with ADL/IADL disability in community dwelling older adults in the Irish longitudinal study on ageing (TILDA). Disabil Rehabil. 2017; 39(8): 809-16.

20. Bean JF, Leveille SG, Kiely DK, Bandinelli S, Guralnik JM, Ferrucci L. A comparison of leg power and leg strength within the InCHIANTI study: which influences mobility more? J Gerontol A Biol Sci Med Sci. 2003; 58(8): 728-33.

21. Wist S, Clivaz J, Sattelmayer M. Muscle strengthening for hemiparesis after stroke: A meta-analisys. Ann Phys Rehabil Med. 2016; 59(2): 114-24.

22. Ouellette MM, LeBrasseur NK, Bean JF, Phillips E, Stein J, Frontera WR et al. A. High-Intensity Resistance Training Improves Muscle Strength, Self-Reported Function, and Disability in Long-Term Stroke Survivors. Stroke. 2004; 35(6): 1404-9.

23. Batchelor FA, Mackintosh SF, Said CM, Hill KD. Falls after stroke. Int J Stroke. 2012; 7(6): 482-90.

24. Kostka J, Czernicki J. The importance of muscle strength and power and the speed of muscle shortening for the ability to maintain balance in patients qualified for rehabilitation. Acta Balneol. 2010; 53(3): 160-8.

25. Kostiukow A, Rostkowska E, Samborski W. Examination of the ability to maintain body balance. Ann Acad Med Stetin. 2009; 55(3): 102-9.

26. West BA, Bhat G, Stevens J, Bergen G. Assistive device use and mobility-related factors among adults aged $\geq 65$ years. J Safety Res. 2015; 55: 147-50.

27. Bateni H, Maki BE. Assistive Devices for Balance and Mobility: Benefits, Demands, and Adverse Consequences. Arch Phys Med Rehabil. 2005; 86(1): 134-45. 